\title{
Synthesis of Eco-Friendly Binders from Natural Resources Using Microwave and their Applications in Textile Printing
}

\author{
N.S Elshemy, W.Niazy, E. M. Khalil*, M. S. Hamed" and \\ K.Haggag \\ Textile Research Division, National Research Center, Cairo, \\ Po. 12622 and *Chemistry Departments, Faculty of Science, \\ Helwan University, Cairo, Egypt.
}

\begin{abstract}
D IFFERENT oil length alkyd resins based on sunflower were prepared using microwave heating the effect of oil length as well as using different catalysts on the .properties of alkyd resin such as acid value, Tg, solubility and IR data were evaluated. In case of using microwave heating the formation of alkyd resin occurred after 45$60 \mathrm{~min}$, while on using conventional heating the reaction duration ranged from 8-10 hr. Also, the prepared alkyds and commercial binder were used separately in the formulation of pigment printing pastes, and the properties of printed fabrics using the prepared binders were found to be comparable with samples printed using the commercial binder.
\end{abstract}

Keywords: Microwave, Binder, Textile printing and Alkyd resins.

The most widely used technique for printing textiles is pigment printing. Aqueous formulation for pigments print pastes typically consist of pigment(s), a suitable thickener, binder and cross linking agents. Because the pigments have almost no affinity for the substrate, the binder and cross linking agents bind the pigments to the surface of the substrate during the heat-curing or fixation step. Binders are also responsible for the hand and many performance properties of the printed textile ${ }^{(1,2)}$.

Binders are highly molecular weight, film-forming polymers that are synthethesized from synthetic vinyl (acrylic) monomers. It was reviewed the attributes of the major monomers used in making binders. The starting materials for these binders are obtained from petroleum a nonrenewable resource. Scarcity of petroleum resources and the rising cost of petroleum products have led to the increasing trend towards development of alternative sources of raw materials for domestic and industrial uses. Renewable resources are now greatly being favored in the production of surface coatings, in preference to petroleum products because of their biodegradable characteristics ${ }^{(3-5)}$. 
The traditional oil seeds such as linseed, soya bean, coconut and castor oil have been commercially used for the synthesis of different kinds of polymeric resins like alkyds, epoxies and polyester amides, a common property of these oils, are their high degree of unsaturation. Alkyd resins are used extensively as binder for formulation of exterior coatings. ${ }^{(6-8)}$.

The principle materials involved in the properties of alkyd resins are polyhydric alcohols and dibasic acid together with modifying oils ${ }^{(9)}$. The development of alkyd resins has taken place largely during the last 38 years and has resulted in new and improved coating composition, adhesive, plastics and textiles. Sunflower seed contains a large amount of oil possessing both saturated and unsaturated fatty acids and hence it may be utilized for the synthesis of alkyd resins binders.

Microwaves are essentially high frequency radiation. The property of microwaves which makes them attractive is their ability under suitable conditions to produce rapid and uniform heating throughout the material exposed to them. Until recently, the reports in their uses in the textiles seem to have been refined to drying processes. Recently, some researchers have studied the feasibility of using microwaves for a variety of textile processes, dyeing, finishing, and printing ${ }^{(10-14)}$ Microwave-assisted organic synthesis has also gained popularity in the recent years because microwave radiations were found to accelerate remarkably a wide variety of reaction, modification of polymer materials, waste water treatment, decompose and de-chlorinate organic substances. Microwave heating is achieved by special oscillator tubes, such as the magnetron, to generate very high frequencies, and the process usually involves an oven or some other clarity. One of the most outstanding advantages of microwave technology is volumetric heating, which minimizes the damage from over-drying. Since heat energy is transferred through the material electron magnetically and not as a heat flux, it is not limited by the volume of the material ${ }^{(11)}$.

Owing to the importance gained by microwave heating and use of natural sources, in the present work different binders were prepared from natural resource using microwave heating.

\section{Materials}

\section{Experimental}

Scoured bleached cotton fabric $100 \%$ (poplin) plain weave $\left(140 \mathrm{~g} / \mathrm{m}^{2}\right)$ and cotton/polyester (35/65) blend fabrics $\left(170 \mathrm{~g} / \mathrm{m}^{2}\right)$ were supplied by Misr Co. for spinning and weaving, Mehalla El-Kubra, Egypt. Technical grade phthalic anhydride, glycerol, benzoic acid, $\mathrm{LiOH}, \mathrm{NaOH}$ and sunflower oil were obtained from commercial sources and used in the alkyds preparation without any further purification. On the other hand as reference and comparison purposes commercial alkyd resins printofix binder MTB-01 EG Liq. and commercial pigment printofix orange HG80-ET, were supplied from EGCODAR. Printofix, Thickener A Liq. as thickener and antifoam PA-NS were supplied from CLARIANT and CIBA, respectively.

Egypt. J. Chem. 53, No.6 (2010) 


\section{Alkyds preparation}

Four different alkyds named as Alk. I, Alk II, Alk. III, Alk. IV with different oil content of $45 \%, 48 \%, 50 \%, 53 \% \mathrm{w} / \mathrm{w}$ were prepared using two stage alcoholysis-polyesterification reaction methods ${ }^{(15)}$. In preparation of each of alkyd, a specific mass of sunflower oil and catalysts were heated to a temperature between $220^{\circ} \mathrm{C}$ and $240^{\circ} \mathrm{C}$ using mechanical stirring. Glycerol anhydrous was added while maintaining the temperature at $240^{\circ} \mathrm{C}$. The amounts of various ingredients are shown in Table 1. The completion of alcoholysis was monitored by taking samples of reaction mixture every $5 \mathrm{~min}$. This sample was mixed with anhydrous methanol 1:1 volume ratio ${ }^{(9)}$. When the mixture present a clear solution, it indicated the end of alcoholysis process and monoglycride was formed. The completion of the alcoholysis stage took $2-3 \mathrm{hr}$ where different amount of phthalic anhydride was added after cooling to $180^{\circ} \mathrm{C}$ and the reaction was continued at $240^{\circ} \mathrm{C}$ for another $6-8 \mathrm{hr}$., The acid value of the reaction mixture was determined by taking a small sample at every one hour. When the acid value was in between 15-75, the reaction mixture was cooled. The acid value is very important it is a measurement of the amount of free acids present in the oil and it is also the number of milligrams of potassium hydroxide required to neutralize the free fatty acids in one gram of sample. Different catalysts (Calcium carbonate, Lithium hydroxide, Sodium hydroxide and Benzoic acid) were used to study the effect of catalyst type.

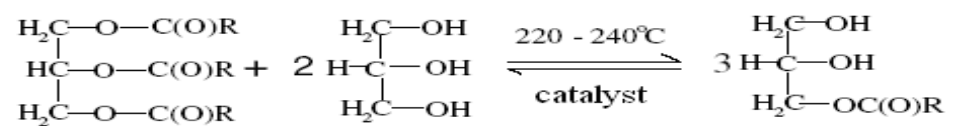

$$
\text { Monoglyceride }+ \text { phthalic acid } \longrightarrow \text { alkyd resin }
$$

The same procedure was repeated in microwave, but the difference was that the alcoholysis time was $15-20 \mathrm{~min}$ and the polyesterification was 20-30 min. The total time taken for the reaction was only 45-60 min in comparison with traditional method. The acid value was determined by taking small sample of the reaction mixture ${ }^{(16)}$.

TABLE 1. Formulation of the different alkyd resins.

\begin{tabular}{|l|c|c|c|c|}
\hline & Alk. I & Alk II & Alk. III & Alk. IV \\
\hline Oil content (\%) & $45 \%$ & $48 \%$ & $50 \%$ & $53 \%$ \\
\hline Phthalic anhydride (g) & $35 \%$ & $32 \%$ & $30 \%$ & $27 \%$ \\
\hline Glycerol anhydrous (g) & $20 \%$ & $20 \%$ & $20 \%$ & $20 \%$ \\
\hline
\end{tabular}

\section{Preparation of printing paste}

The printing pastes were prepared according to the formulation given in Table 2 . Antifoam, urea and binder were mixed together with distilled water. The synthetic thickener was then introduced and the paste was stirred using a high 
shear mixer for 10 min to allow full viscosity to develop. The pigment was then added to the mixture with stirring using the previous mixer for $15 \mathrm{~min}$.

TABLE 2. Formulation of the printing paste.

\begin{tabular}{|c|c|}
\hline Component & g/100 \\
\hline Water & $\mathrm{y}$ \\
\hline Binder & $\mathrm{X}$ \\
\hline Thickener & 1.5 \\
\hline Anti-foam PA-NS & 0.2 \\
\hline Urea & 4 \\
\hline Pigment & 4 \\
\hline Total & $100 \mathrm{~g}$ \\
\hline
\end{tabular}

\section{Printing technique}

The printing of fabrics was carried out using screen printing machine, type VP-AL-500, Germany, and air dried the printed fabrics were subjected to thermal treatment in a thermostatic oven (Mathis, Switzerland) to fix the color through polymerization process. The printed fabrics were washed and rinsed thoroughly with cold water before being treated with hot water to remove the residual unfixed dye.

\section{Evaluation of alkyd resins \\ IR spectroscopy}

The prepared binders were measured using Perkin Elmer, system 2000 FT-IR (Fourier transform IR spectrometer) in thin film form ${ }^{(7)}$.

\section{Acid value}

The acid value is the number of milligrams of potassium hydroxide necessary to neutralize fatty acids in 1 gram of sample. The sample is weighed in an Erlenmeyer flask, diluted with neutral alcohol, and titrated with $0.1 \mathrm{~N}$ methanolic potassium hydroxide $(\mathrm{KOH})$ or $0.5 \mathrm{~N}$ aqueous sodium hydroxide $(\mathrm{NaOH})$, depending on the expected acid value $15-75^{(16)}$.

$$
\text { Acid value, } m g \frac{K O H}{g m}=\frac{(m l \text { of titrant })(N \text { of titrant })(56.1)}{(\text { Sample } W t .)}
$$

\section{Water absorbency of the binder films}

Films of four prepared binders containing different amounts of oil content Alk. I, Alk II, Alk. III, Alk. IV and the commercial binder were prepared by pouring the binders in Petri dishes and left to dry in air. The formed films were cured for $4 \mathrm{~min}$ at $160^{\circ} \mathrm{C}$ and then left to cool at room temperature for $24 \mathrm{hr}$. The weight of each binder's film was weighed (W) accordingly. The films were then immersed in distilled water for different intervals of 6, 12, 24 and $48 \mathrm{hr}$ at room temperature. The surface water was then removed by a filter paper and the

Egypt. J. Chem. 53, No.6 (2010) 
swollen film was reweighed (W1).The water absorbency (\%) was calculated according to Eq. $4^{(17)}$.

$$
\text { Water absorbency }(\%)=\frac{W 1-W}{W} \times 100
$$

where: $\mathrm{W}=$ the weight of the original sample

$\mathrm{W} 1=$ the weight of the swollen sample

Weight loss of the binder films under the action of water

All binders were prepared as discussed above. The formed films were cured for $4 \mathrm{~min}$ at $160^{\circ} \mathrm{C}$, then left to cool at room temperature for $24 \mathrm{hr}$. The films were weighed $(\mathrm{W})$, then treated with distilled water for different periods $24 \mathrm{hr}$ and $48 \mathrm{hr}$ and left to dry at room temperature for $24 \mathrm{hr}$ and weighed (W2). The loss in weight was calculated according to Eq. $5^{(17)}$.

$$
\text { Weight loss }(\%)=\frac{W-W 2}{W} \times 100
$$

Where : $\mathrm{W}=$ the dry weight of the film before treatment with water

$\mathrm{W}_{2}=$ the dry weight of the film after treatment with water

Glass transition temperature $(\mathrm{Tg})$

The $\mathrm{Tg}$ of the binder was measured by differential scanning calorimetry (DSC) Shimadzu - 50.

\section{Rheological measurement}

The rheological properties and apparent viscosity of prepared binders were measured at $25^{\circ} \mathrm{C}$ according to a procedure reported elsewhere ${ }^{(18)}$ by dissolving the purified samples in distilled water at a concentration of $3 \%(\mathrm{v} / \mathrm{v})$ using Programmable Rheometer, Brookfield model DV-111, U.S.A. at different rates of shear range between $0.27-17 \mathrm{~s}^{-1}$.

The apparent viscosity was calculated using the following formula:

$$
\eta=\tau / D
$$

where $\eta=$ apparent viscosity in poise.

$$
\begin{aligned}
& \tau=\text { shearing stress }\left(\text { dyne } / \mathrm{cm}^{2}\right) . \\
& D=\text { rate of shear }\left(\mathrm{s}^{-1}\right)
\end{aligned}
$$

\section{Evaluation of printed fabric}

Color measurements

The relative color strength of the prints, expressed as K/S value ${ }^{(19)}$ of the printed samples was determined by reflection measurements using Data Color International SF 500, USA.

\section{Roughness measurements}

The effect of prepared binder with different oil content and commercial ene binder on the surface roughness of printed fabric was measured by using Surface Roughness Measuring Instrument SE 1700 $\alpha$. 


\section{Fastness properties}

Fastness properties to washing, rubbing and perspiration were measured according to the standard method ${ }^{(20)}$. Color fastness to light was determined according to ISO test method 105-B01. The evaluation was carried out using the gray scale reference for color change ${ }^{(21-22)}$.

\section{Results and Discussion}

Four alkyd resins were prepared using the same procedure and the same reagents but with different oil content and different catalytic systems.

\section{Characterization of the prepared alkyd resins}

The physicochemical and film properties of the prepared binders namely the final acid value, water absorbance, weight loss, IR spectroscopy, glass transition temperature $\mathrm{Tg}$, rheological properties and viscosity were investigated.

\section{Acid value}

A two stage alcoholysis - polyesterification method was used to prepare four alkyd resins, (Alk.I, Alk.II, Alk.III and Alk.IV), in the presence of different type of catalysts such as $\left(\mathrm{LiOH}, \mathrm{NaOH}, \mathrm{CaCO}_{3}\right.$ and benzoic acid) using microwave. The mentioned alkyds are different in the content of oil which is one important variable to be investigated in the study of alkyd resins formulation. The acid number is a measure of the amount of carboxylic acid groups in a chemical compounds, such as fatty acid, or in a mixture of compounds. The relationship between the percentage of oil used in the alkyd formula and acid value is shown in Fig.1 and Table 3. It was observed that the reaction using $\left(\mathrm{CaCO}_{3}\right.$, benzoic acid) was uncompleted but the acid value of reaction mixtures using $(\mathrm{LiOH}, \mathrm{NaOH})$ was increased with increasing of oil content. This may be attributed to the decrease in concentration of free fatty acid and its conversion to ester. The highest initial acid value was observed in the alkyd mixture which contains the highest amount of oil.

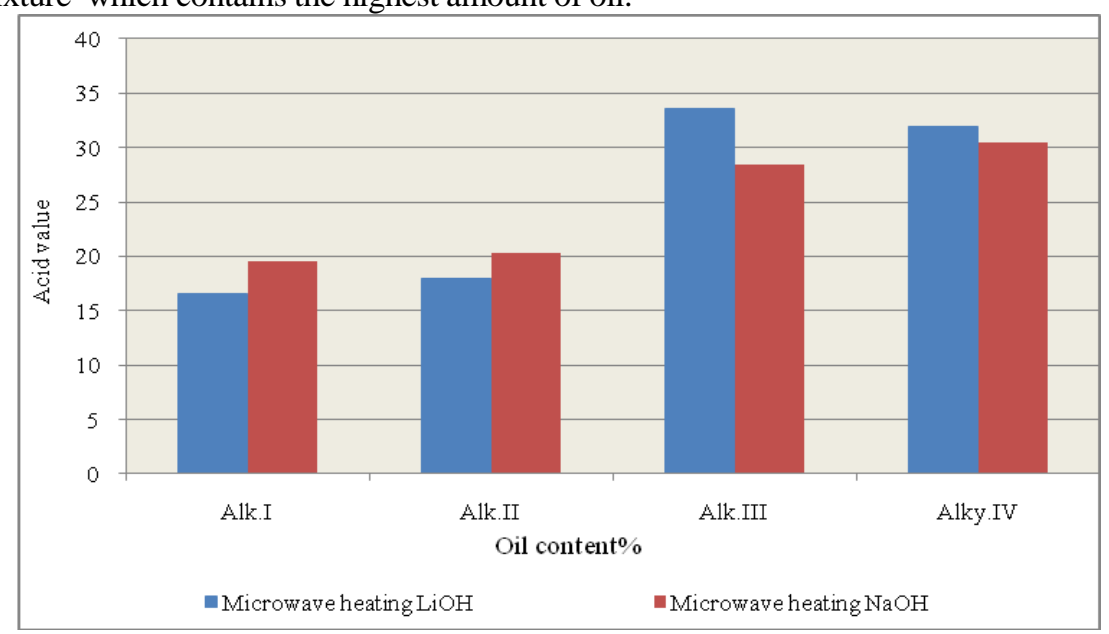

Fig.1. Acid value versus oil content.

Egypt. J. Chem. 53, No.6 (2010) 
TABLE 3. Effect of oil content on reaction time, acid value and $\mathrm{Tg}$ of prepared binder using microwave heating.

\begin{tabular}{|c|c|c|c|c|c|c|c|c|c|c|}
\hline \multirow{2}{*}{ Oil content $\%$} & \multicolumn{2}{|c|}{$\begin{array}{l}\text { Alcoholysis } \\
\text { step }\end{array}$} & \multicolumn{2}{|c|}{$\begin{array}{c}\text { Esterification } \\
\text { step }\end{array}$} & \multicolumn{2}{|c|}{$\begin{array}{c}\text { Total } \\
\text { time/min. }\end{array}$} & \multicolumn{2}{|c|}{ Acid value } & \multicolumn{2}{|c|}{$\mathbf{T g}$} \\
\hline & (a) & (b) & (a) & (b) & (a) & (b) & (a) & (b) & (a) & (b) \\
\hline 45 & 15 & 17 & 30 & 33 & 45 & 50 & 16.6 & 19.5 & 2.70 & 4.21 \\
\hline 48 & 16 & 18 & 32 & 34 & 48 & 52 & 18.0 & 20.3 & 2.96 & 3.70 \\
\hline 50 & 19 & 19 & 37 & 35 & 56 & 54 & 33.6 & 28.4 & 5.71 & 4.48 \\
\hline 53 & 20 & 21 & 40 & 36 & 60 & 57 & 31.9 & 30.5 & 4.90 & 4.54 \\
\hline
\end{tabular}

$\mathrm{a}=(\mathrm{LiOH}), \mathrm{b}=(\mathrm{NaOH})$.

\section{Rheological properties of the prepared binders}

The rheological properties of the prepared binders and their viscosity are responsible for controlling dye penetration, depth of shade, sharpness of the print and levelness, so it is of great interest to investigate the rheological properties of the prepared binders. The rheological properties and viscosity of prepared binder containing different amount of oil (using microwave irradiation) were shown in Fig. 2 and Table 4. It is clear that all samples examined were characterized by non-Newtonian pseudo plastic behavior, where the up and down flow curves are coincident. It is also clear that the location of the rheogram and its slope seems to be dependent on the catalysts type, and oil content which indicates a variation in the apparent viscosity. The rheogram curve of the commercial binder Printofix Binder MTBOL EG Liq used was shifted nearest to the axis of the rate of shear indicating a decrease in its apparent viscosity as shown in Fig. $2 \& 3$ whereas by using prepared binders, the rheogram curves were shifted far from the axis of the rate of shear indicating an increase in its apparent viscosity. This is may be attributed to microwave irradiation effect on prepared binders.

TABLE 4. Effect of oil content on apparent viscosity of prepared and commercial binders.

\begin{tabular}{|c|c|c|c|c|c|c|c|c|c|}
\hline \multirow{2}{*}{$\begin{array}{c}\text { Rate of } \\
\text { shear } \\
\left(\mathbf{S e c}^{-1}\right)\end{array}$} & \multicolumn{7}{|c|}{ Alk. I } & \multicolumn{7}{|c|}{ Alk. II } & \multicolumn{2}{|c|}{ Alk. III } & \multicolumn{2}{|c|}{ Alk. IV } & \multirow{2}{*}{$\begin{array}{c}\text { Commercia } \\
\text { I binder }\end{array}$} \\
\cline { 2 - 9 } & $\mathbf{L i O H}$ & $\mathbf{N a O H}$ & $\mathbf{L i O H}$ & $\mathbf{N a O H}$ & $\mathbf{L i O H}$ & $\mathbf{N a O H}$ & $\mathbf{L i O H}$ & $\mathbf{N a O H}$ & \\
\hline 0.35 & 435.00 & 335.10 & 83.33 & 79.12 & 111.20 & 115.00 & 45.98 & 48.18 & 14 \\
\hline 0.51 & 433.33 & 333.00 & 83.24 & 75.00 & 108.98 & 114.17 & 43.73 & 47.92 & 9 \\
\hline 0.68 & 428.75 & 322.21 & 82.92 & 73.96 & 105.81 & 112.86 & 42.89 & 47.86 & 8.5 \\
\hline 0.85 & 428.60 & 317.40 & 82.52 & 73.34 & 105.34 & 111.88 & 42.46 & 47.80 & 7.8 \\
\hline 1.02 & 428.33 & 309.11 & 82.20 & 72.87 & 104.78 & 111.11 & 42.32 & 47.71 & 6.9 \\
\hline 1.19 & 427.78 & 301.23 & 82.11 & 72.31 & 104.11 & 111.00 & 41.95 & 46.92 & 5.85 \\
\hline
\end{tabular}

Egypt. J. Chem. 53, No.6 (2010) 
The apparent viscosities at various rates of shear were calculated from the values of shearing stress and rate of shear. The data obtained are given in Table 4. It can be seen that the apparent viscosity decreases as the rate of shear increases (prepared binders show thinning down). Viscosity of prepared binders are higher than that of the commercial one which reduces the amount of used thickener in the printing pastes. It can also be seen that the values are higher when using $\mathrm{LiOH}$ as catalyst with Alk. I and Alk. II, but for Alk. III and Alk. IV, $\mathrm{NaOH}$ added as catalyst produced higher viscosity than $\mathrm{LiOH}$ as catalyst. This may be attributed to the higher alkalinity of $\mathrm{NaOH}$ than that of $\mathrm{LiOH}$, so it can affect the longer oil content.

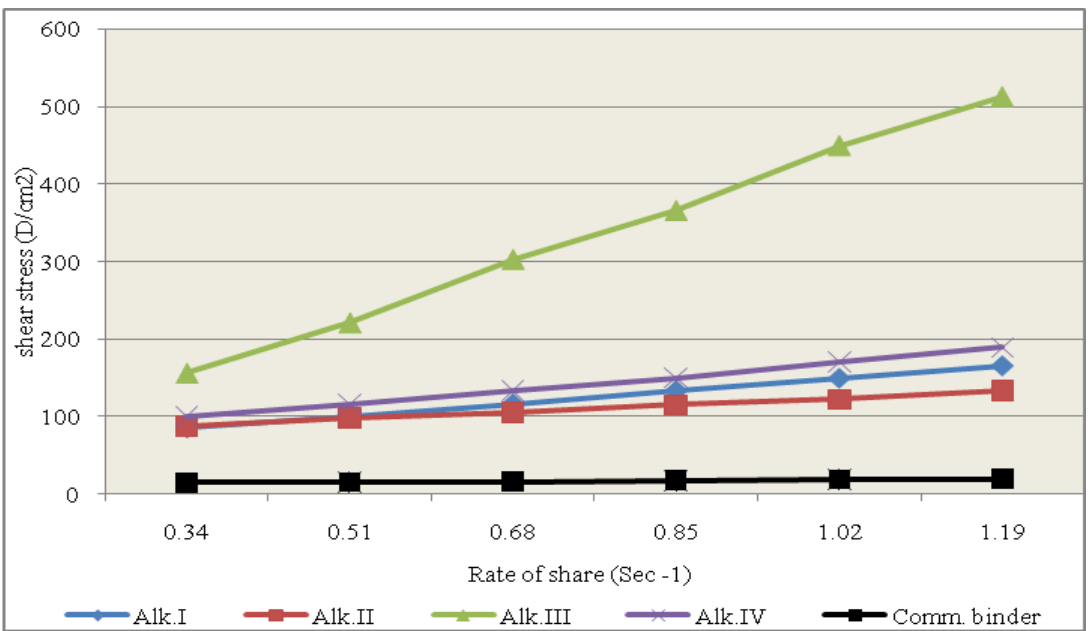

Fig. 2. Rheological properties of prepared and commercial binders using microwave irradiation with $\mathrm{LiOH}$ as catalysts.

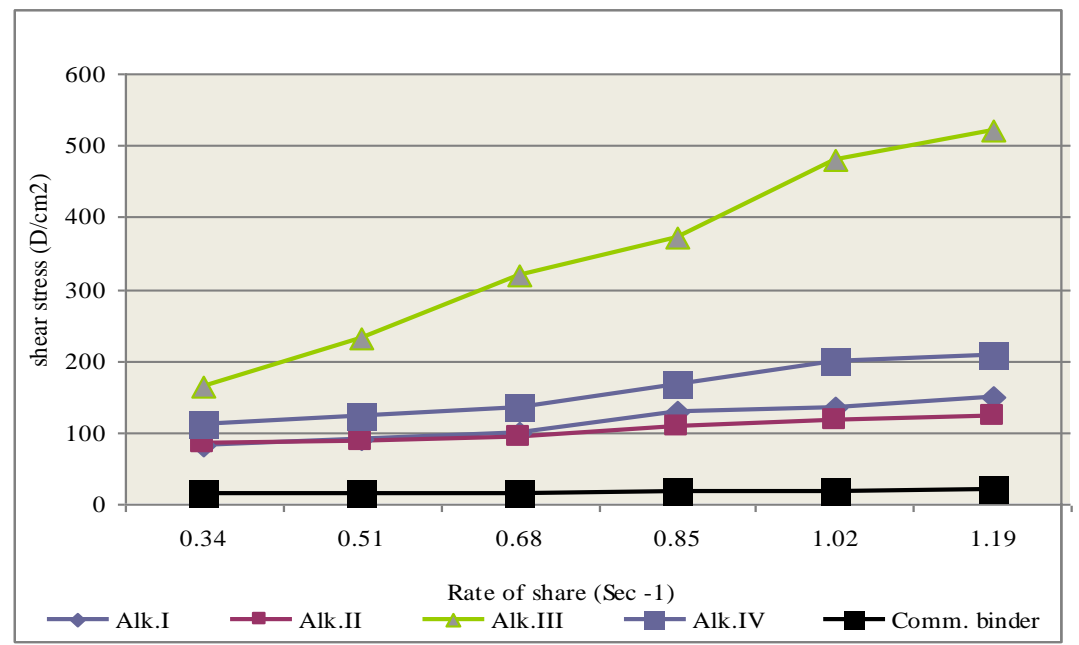

Fig. 3. Rheological properties of prepared and commercial binders using microwave irradiation with $\mathrm{NaOH}$ as a catalysts.

Egypt. J. Chem. 53, No.6 (2010) 
IR Spectroscopy

Chemical structure of prepared binders using microwave heating in the presence of $\mathrm{LiOH}$ (Alk. I, II) and $\mathrm{NaOH}$ (Alk. III, IV) was measured using IR spectroscopy. The IR data of the different prepared alkyd resins indicate the presence of important linkage such as ester groups, olefinec double bonds and other characteristic peaks. The spectra of samples, (Fig. 4-7) shows slight difference in the intensity of $\mathrm{C}=\mathrm{O}$ stretching vibration. From the figures it can be noticed that the formation of ester group $(\mathrm{O}-\mathrm{C}=\mathrm{O})$ and the carbonyl stretching $\mathrm{C}=\mathrm{O}$ of aliphatic ester appears from $1750-1735 \mathrm{~cm}^{-1}$. while $\alpha-\beta$ unsaturated ester appears from 1735-1722 $\mathrm{cm}^{-1}$ and C-O stretches appears as two or one bands in region 1300-1000 $\mathrm{cm}^{-1}$. This means the end of alcoholysis-polyesterification reaction where alkyd resins were formed. These results reveal that the resins are formed through ester linkage of oil and the anhydrides.

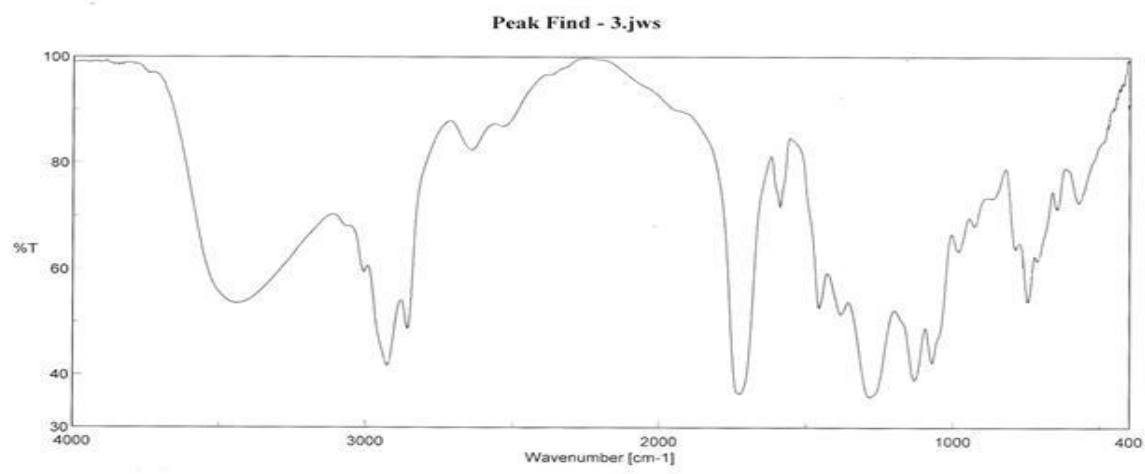

Fig. 4. IR spectra of Alk. I in the presence of LiOH as catalyst.

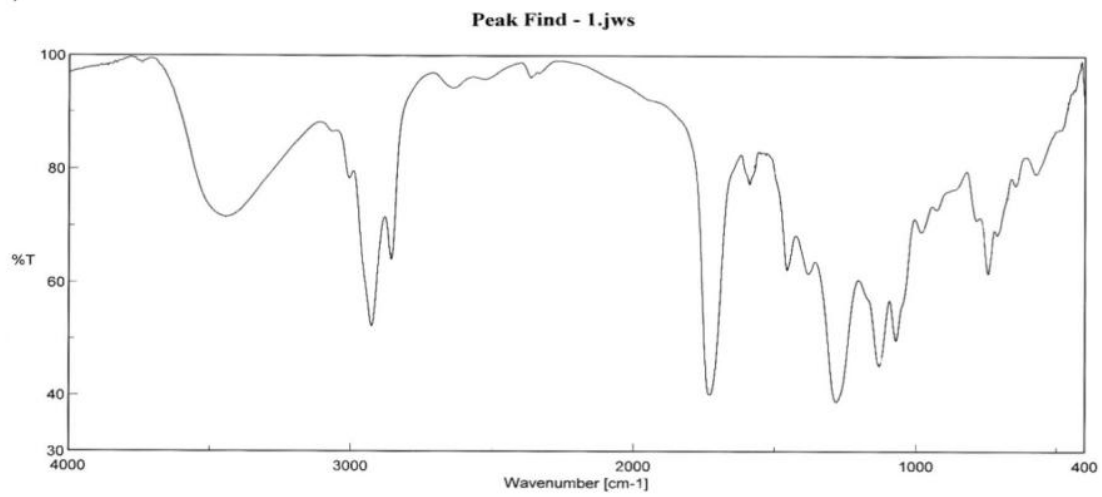

Fig. 5. IR spectra of Alk. II in the presence of $\mathrm{LiOH}$ as catalyst. 


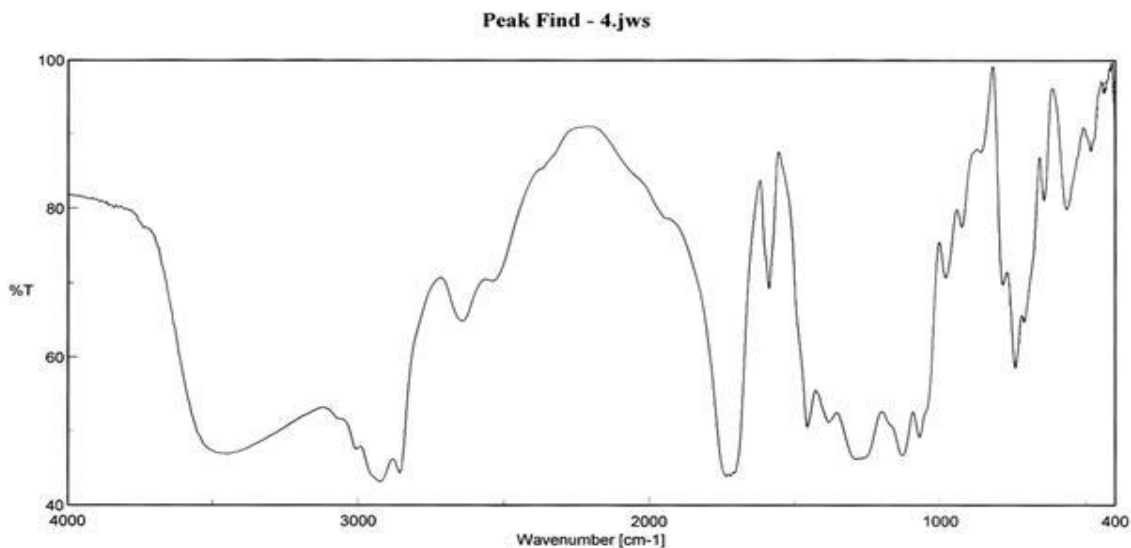

Fig. 6. IR spectra of Alk. III in the presence of $\mathrm{NaOH}$ as catalyst.

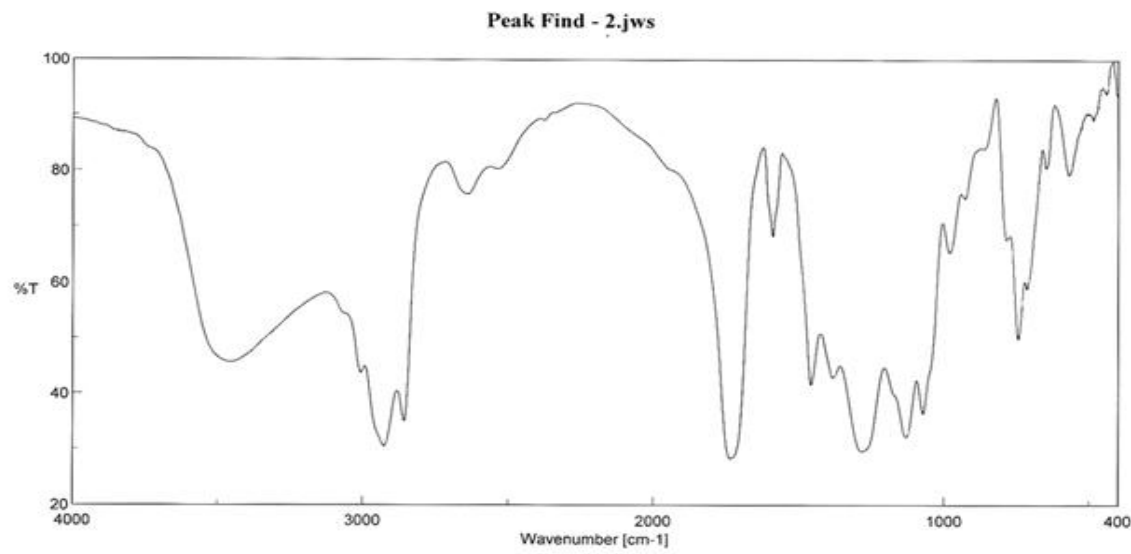

Fig. 7. IR spectra of Alk. IV in the presence of $\mathrm{NaOH}$ as catalyst.

Effect of oil content on water solubility (weight loss) of the prepared binder

Length of oil (short, medium and long alkyd resins) is an important variable to be investigated in the study of alkyd resins formulation. From Fig. 8 it can be noticed that the weight loss of prepared binder film decreases as the oil content increases. This may be attributed to the formation of ester groups. The small esters are fairly soluble in water but solubility falls with chain length. One of the slightly positive hydrogen atoms in a water molecule can be sufficiently attracted to one of the lone pairs on one of the oxygen atoms in an ester for a hydrogen bond to be formed. There will also, of course, be dispersion forces and dipoledipole attractions between the ester and the water molecules. Forming these attractions releases energy. This helps to supply the energy needed to separate water molecule from water molecule and ester molecule from ester molecule

Egypt. J. Chem. 53, No.6 (2010) 
before they can mix together. As chain lengths increase, the hydrocarbon parts of the ester molecules start to get in the way. By forcing themselves between water molecules, they break the relatively strong hydrogen bonds between water molecules without replacing them. This makes the process energetically less profitable, and so solubility decreases.

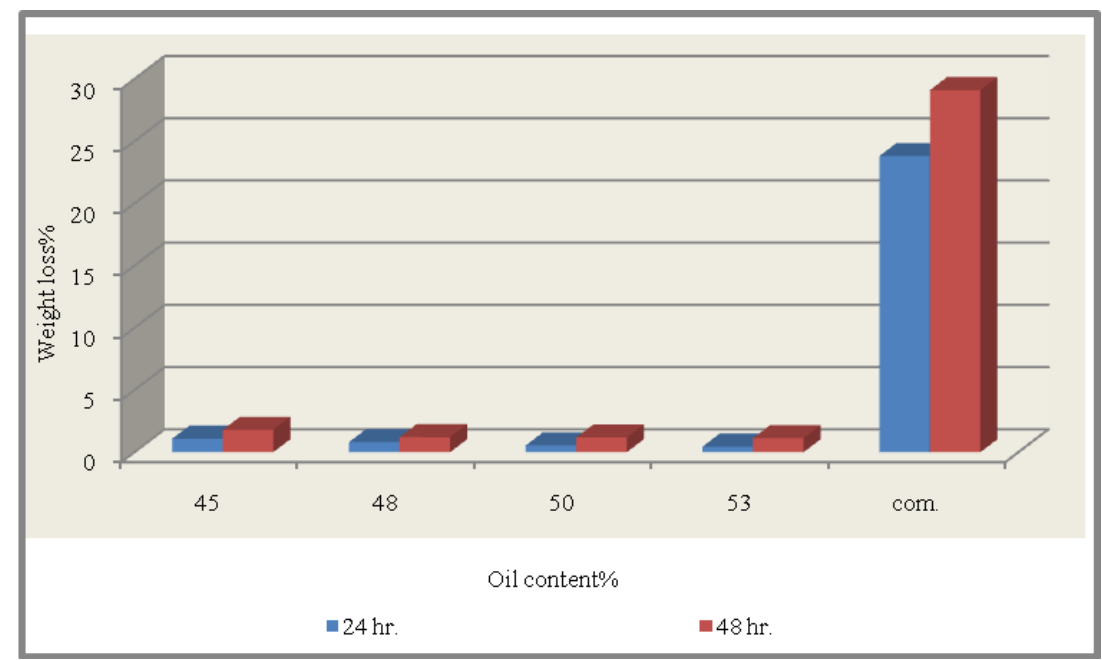

Fig.8. Effect of oil content on weight loss of prepared and commercial binders.

Effect of oil content on the water absorption of the prepared binder films

This experiment was carried out to measure the water absorption of prepared binders' film using microwave heating. From Fig. 9, it can be deduced that the water absorption of the binder film decreases as oil content increases. Also, the water absorbance is lower in case of prepared binder than the commercial one. This may be attributed to the formation of ester group, as mentioned above.

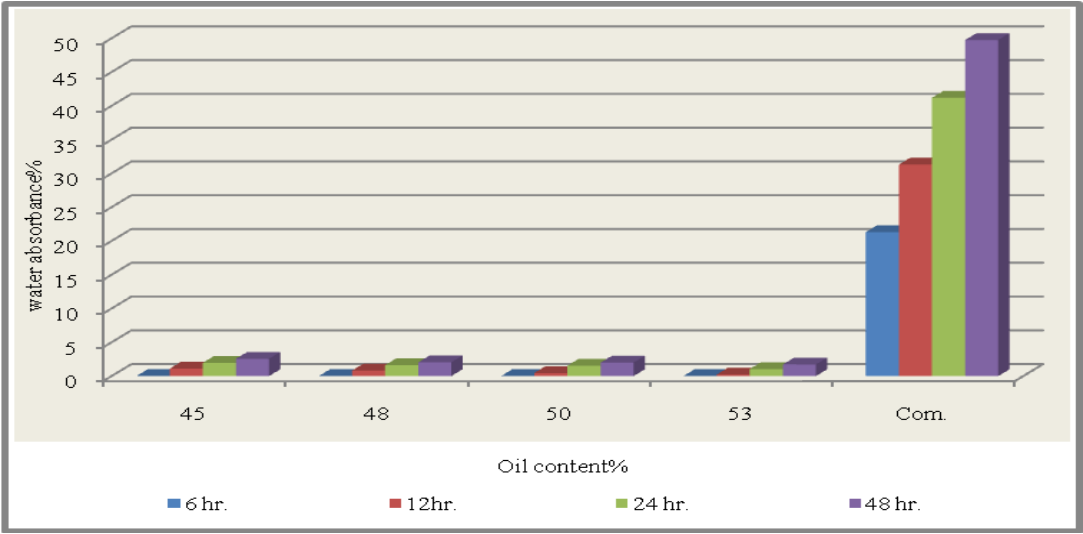

Fig.9. Effect of oil content on water absorbance of prepared and commercial binders.

Egypt. J. Chem. 53, No.6 (2010) 
Glass Transition Temperature ( $\mathrm{Tg}$ )

At low temperatures, all amorphous polymers are stiff and glassy, but on warming polymers soften in a characteristic temperature range known as the glass-rubber transition region. The glass transition temperature $(\mathrm{Tg})$, is the temperature at which the amorphous phase of the polymer is converted between rubbery and glassy states. $\mathrm{Tg}$ constitutes the most important mechanical property for all polymers. In fact, upon synthesis of a new polymer, the glass transition temperature is among the first properties measured ${ }^{(23)}$. For a pigment printing binder, the $\mathrm{Tg}$ of the polymer can be varied from $-40^{\circ} \mathrm{c}$ to $+15^{\circ} \mathrm{c}$.

In this study it was found that the $\mathrm{Tg}$ of different prepared binders ranges from $+2.7:+5.7$ and commercial binder was -14 which indicates that the glassy state of binders is typically formed by cooling to very low temperature where polymers solidify molten or liquid state, so the printing pastes which contain these binders will keep its viscosity at wide range of temperature.

Effect of catalysts type on the synthesis of modified alkyd resins and reaction time

Alkyd resins can be classified in terms of their oil length, that is, the amount of oil they contain:

- Short oil contains less than $45 \%$

- Medium oil contains 45-55\%.

- Long oil contains greater than 55\% (24).

Some alkyd resins with different oil content were prepared using the same procedure with the same reagents but different concentrations and different catalysts ( $\mathrm{LiOH}, \mathrm{NaOH}, \mathrm{CaCO}_{3}$ and benzoic acid) in the alcoholysis stage. No additional catalyst was used in the esterfication stage. The results of the alcoholysis-esterification reaction time and over all process time for each catalytic system are shown in Table 3.

It was observed that the total time of the preparation increases with increasing oil content of alkyd irrespective of catalyst type which need more time to complete the reaction. Use of microwave irradiation reduces the reaction time to be in the range of 45-73 min (Table 3) while for conventional heating the reaction time reaches ten hours with separation of oil. The direct heating of molecules under microwave irradiation leads to very fast and homogeneous heating that has resulted in the reduction of side reactions, cleaner products and higher yields. Microwave heating is based on dielectric heating, i.e., molecules exhibiting a permanent dipole moment will try to align to the applied electromagnetic field resulting in rotation, friction and collision of molecules thus generate heat. As a result, the heating rate and efficiency of microwave heating strongly depend on the dielectric properties and the relaxation times of the reaction mixture. Besides the advantages of fast and homogeneous heating as well as the possible high-temperature chemistry, non-thermal microwave effects due to specific heating of polar intermediates have also been observed, e.g., leading to modified selectivity and enabling reactions that cannot be performed with

Egypt. J. Chem. 53, No.6 (2010) 
thermal heating ${ }^{(25,26)}$. In order to study the effect of catalyst types, four catalysts were used in alcoholysis step, $\mathrm{LiOH}, \mathrm{NaOH}, \mathrm{CaCO}_{3}$ and benzoic acid. It was observed that by using $\mathrm{LiOH}$ and $\mathrm{NaOH}$ the reaction was more successful. While by using $\mathrm{CaCO}_{3}$ and benzoic acid the reaction was uncompleted. Turbidity appeared when using $\mathrm{CaCO}_{3}$, but by using benzoic acid the alkyd was separated from the oil due to its acidity. Catalysts which generally alkaline $e . g . \mathrm{LiOH}$ and $\mathrm{NaOH}$ in alcoholysis step were more effective than the acidic one ${ }^{(27)}$.

Application of prepared binder in textile pigment printing

Colour strength of pigment printed cotton, cotton/polyester fabrics using the different prepared binders

Depth of shade presented in Table 5 are the K/S values for the pigment printed fabrics using alkyds with different oil content in the formulation of the printing paste and in presence of different catalysts. In general, the K/S values of printed fabrics using pastes containing short oil alkyd binders were lower than those obtained using commercial one. However, the medium oil alkyd binder resulted in higher K/S values.

TABLE 5. Effect of oil content on color strength of printed cotton and cotton/polyester blend fabric using pigment dyes.

\begin{tabular}{|l|c|c|c|c|}
\hline \multirow{2}{*}{ Oil content \% } & \multicolumn{4}{|c|}{ Color strength K/S } \\
\cline { 2 - 5 } & \multicolumn{3}{|c|}{ Cotton } & Cotton/polyester \\
\cline { 2 - 5 } & LiOH & NaOH & 7.64 & NaOH \\
\hline 44 & 6.84 & 6.05 & 10.44 & 9.01 \\
\hline 45 & 9.66 & 8.11 & 10.30 & 10.32 \\
\hline 48 & 11.33 & 9.95 & 10.25 & 13.27 \\
\hline 50 & 10.12 & 10.48 & 10.11 & 11.32 \\
\hline 53 & 8.71 & 12.00 & \multicolumn{2}{c|}{9.65} \\
\hline Comm. & \multicolumn{3}{|c|}{9.17} & \\
\hline
\end{tabular}

From the results listed in Table 5 we can observe that:

- The color strength (K/S) depended on the fabric type, catalyst used and oil content of alkyd resin.

- The K/S increased as oil content increased.

- The best K/S were obtained at oil content of $45 \%$ and $48 \%$ in the presence of $\mathrm{LiOH}, 50 \%$ and $53 \%$ in the presence of $\mathrm{NaOH}$, for cotton/polyester blend and cotton fabric, respectively.

Effect of binder content in printing paste

The effect of binder content in printing paste was studied. Fig.10 illustrates the effect of binder $(1-30 \%)$ in printing paste on color strength of printed cotton and/or cotton/polyester blend fabrics using pigment. From Fig. 10 it was observed that the color strength increases as binder content increases in

Egypt. J. Chem. 53, No.6 (2010) 
printing paste reaching 5\% then it decreases irrespective of fabric and catalyst types. So it can be concluded that the optimum concentration of binder was $5 \%$.

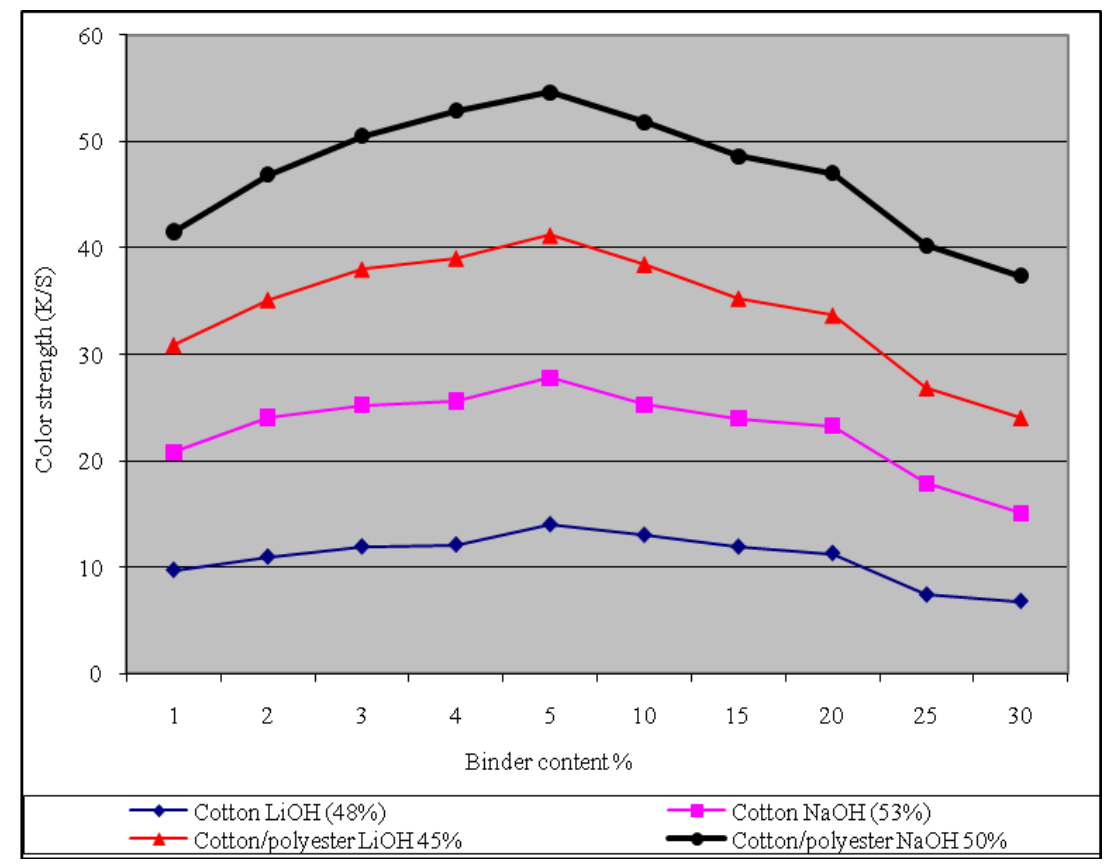

Fig.10. Effect of binder\% in printed paste on color strength of printed cotton and cotton/polyester fabric using pigments.

\section{Determination of the optimum fixation conditions}

Figures 11 and 12 show the color strength values of prints using different pastes including the prepared binders (oil content $45 \%, 48 \%, 50 \%$ and $53 \%$, $\mathrm{LiOH}$ and $\mathrm{NaOH}$ as catalysts) for the two fabrics. The fabric printing process was carried out using screen printing technique and the goods were dried in air then subjected to thermal treatment at different temperature (120, 140, $160^{\circ} \mathrm{C}$ ) and for different intervals of times (2, 4, 6 min.). From the figures it can be observed that cotton fabric has the highest color strength at fixation temperature of $140^{\circ} \mathrm{C}$ for 2 min using $48 \% \mathrm{LiOH}$ and $160^{\circ} \mathrm{C}$ for $4 \mathrm{~min}$. when using $53 \% \mathrm{NaOH}$. On the other hand cotton/polyester fabric obtained the highest color strength at $140^{\circ} \mathrm{C}$ for 6 min when using $45 \% \mathrm{LiOH}$ and at $140^{\circ} \mathrm{C}$ for 4 min when $50 \% \mathrm{NaOH}$ was used. It can be seen from the figures that the commercial binder under the same conditions shows lower color strength irrespective of fixation conditions. 


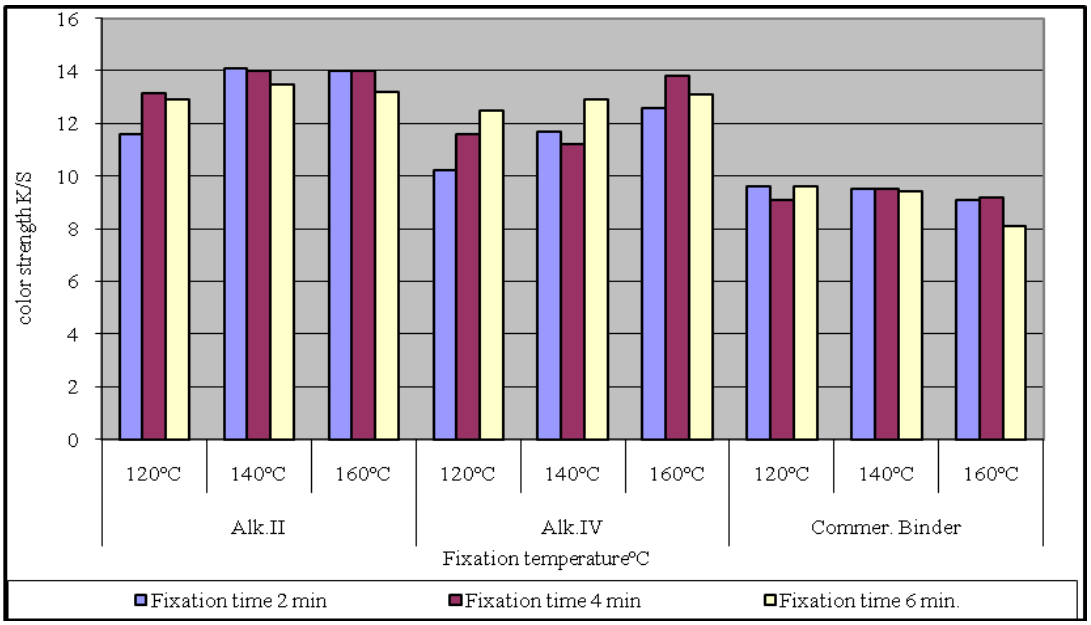

Fig. 11. Effect of fixation time and temperature on color strength of printed cotton fabric using pigment.

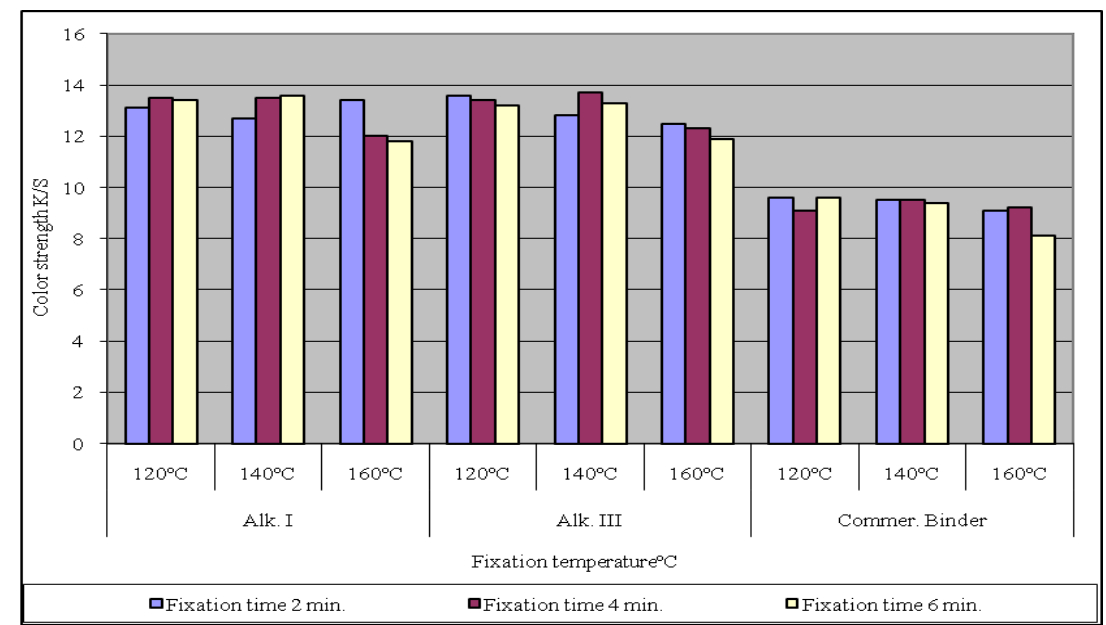

Fig. 12. Effect of fixation time and temperature on color strength of printed cotton/polyester blends fabric using pigment.

\section{Fastness properties}

Table 6 shows the roughness and overall fastness properties of printed cotton and/or cotton/polyester blend fabric using 5\% prepared binders (Alk. I, Alk. II, Alky. III, Alk. IV) and the commercial binder. 
TABLE 6. Roughness and overall fastness properties of printed cotton and cotton/polyester blend fabric using $5 \%$ of prepared and commercial binders.

\begin{tabular}{|c|c|c|c|c|c|c|c|c|c|c|}
\hline \multirow{3}{*}{ Binder used } & \multicolumn{2}{|c|}{$\begin{array}{l}\text { Rubbing } \\
\text { fastness }\end{array}$} & \multicolumn{2}{|c|}{$\begin{array}{l}\text { Washing } \\
\text { fastness }\end{array}$} & \multicolumn{4}{|c|}{ Perspiration fastness } & \multirow{3}{*}{$\begin{array}{c}\text { Light } \\
\text { fastness }\end{array}$} & \multirow{3}{*}{ Roughness } \\
\hline & \multirow{2}{*}{ Dry } & \multirow{2}{*}{ Wet } & \multirow{2}{*}{ Alt. } & \multirow{2}{*}{ St. } & \multicolumn{2}{|c|}{ Acid } & \multicolumn{2}{|c|}{ Alkaline } & & \\
\hline & & & & & Alt. & St. & Alt & St. & & \\
\hline \multicolumn{11}{|c|}{ Cotton fabric (100\%) } \\
\hline $\begin{array}{c}\text { Commercial } \\
\text { binder }\end{array}$ & $3-4$ & 2 & 2 & $2-3$ & $2-3$ & 2 & 2 & 2 & $6-7$ & 16.26 \\
\hline Alky.II & $4-5$ & 4 & $4-5$ & $4-5$ & 5 & $4-5$ & $4-5$ & 5 & $6-7$ & 9.605 \\
\hline Alk.IV & $4-5$ & 4 & $4-5$ & $4-5$ & $3-4$ & 3 & $3-4$ & 4 & $6-7$ & 9.805 \\
\hline \multicolumn{11}{|c|}{ Cotton/polyester blend fabric $(35 / 65)$} \\
\hline $\begin{array}{c}\text { Commercial } \\
\text { binder }\end{array}$ & $2-3$ & 13 & 4 & 4 & 2 & 2 & $2-3$ & $2-3$ & $6-7$ & 21.28 \\
\hline Alk.I & 4 & 4 & $4-5$ & 5 & 5 & $4-5$ & $4-5$ & 5 & $6-7$ & 17.18 \\
\hline Alk.III & $4-5$ & 4 & 4 & 5 & $3-4$ & $3-4$ & 4 & 4 & $6-7$ & 16.73 \\
\hline
\end{tabular}

The washing fastness at $60^{\circ} \mathrm{C}$, Alt $=$ Alteration, St. $=$ Staining, fixation temperature for Alk.I $140^{\circ} \mathrm{C}$ for $2 \mathrm{~min}$, Alk. II. $160^{\circ} \mathrm{C}$ for 4 min., Alk.III $140^{\circ} \mathrm{C}$ for 6 min ,Alk .IV $140^{\circ} \mathrm{C}$ for $4 \mathrm{~min}$ and for commercial binder $140^{\circ} \mathrm{C}$ for 4 .

The data listed in Table 6 shows that the roughness and overall properties depend on the type of fabric and binder used in printing pastes. The rubbing, washing and perspiration fastness ranged from good to excellent in the case of prepared binders, while the ranges were from poor to good in the case of commercial binder. All the prints have excellent fastness to light. and Roughness results show that all samples show soft handle, except in commercial binder where the handle is harsh.

\section{Conclusion}

Modified alkyd resins from sunflower oil have been successfully used as binders in the formulation of pigment printing pastes. They were characterized by non-Newtonian pseudo plastic behavior, weight loss, and water absorption which were indirectly proportion to the oil content and $\mathrm{Tg}$ of the prepared binders. $\mathrm{Tg}$ was in the range of $+2.5:+5.7$ which indicates the glassy state of binders typically formed by cooling to very low temperature.

The use of microwave irradiation to prepare the alkyd resins reduces reaction time to be in the range of 45-60 min, while separation of oil occurred at reaction time of 8-10 hr in the case of conventional heating.

Color strength and overall fastness properties of the prints were comparable or better than commercial binder. 


\section{References}

1. Lin, K.F. and Kirk-Othmer, "Encyclopedia of Chemical Technology" Alkyd resin, $4^{\text {th }}$ ed by M. Howe-Grant, John Wiley \& Sons, New York, Vol. 2, 53 (1992).

2. Weiss, K.D. Paint and coatings: A mature industry in transition. Prog Polym Sci, 22, 203-45 (1997).

3. Dutta, N., Karak, N. and Dolui, S.K., Synthesis and characterization of polyester resins based on Nahar seed oil. Journal of Progress in Organic Coatings, 49, 146-152 (2004).

4. Spyros, A., Quantitative determination of the distribution of free hydroxylic and carboxylic groups in unsaturated polyester and alkyd resin by 31 P-NMR spectroscopy. Journal of Applied Polymer Science, 83, 1635-42, $22^{\text {nd }}$ February (2002).

5. a) Giguere, R. J., Bray, T. L., Duncan, S. M. and Majetich, G.,Tetrahedron Lett. 27, 4945-4948 (1986), b) Gedye, R., Smith, F., Westaway, K., Ali, H., Baldisera, L. and Laberge, L., Rousell, J. Tetrahedron Lett. 27, 279-282 (1986).

6. a) Loupy, A., Petit, A., Hamelin, J., Texier-Boullet, F., Jacquault, P. and Mathé, D., Synthesis 1213-1234 (1998), b) Varma, R. S. Green Chem. 43-48 (1999) c)Kidwai, M., Pure Appl. Chem. 73, 147-151 (2001) d) Varma, R. S., Pure Appl. Chem. 73, 193-198 (2001)

7. Tapan Kanai, T.K. and Mahato. Dhirendra Kumar, Synthesis and characterization of novel silicone acrylate-soya alkyd resin as binder for long life exterior coatings. Progress in Organic Coating, 58, 259-264 (2007).

8. Abo, M., Akira, M., Mano, K. and Sakaguchi, K., Japan Pat.75 28, 986 (1975),Chem. Abstr. 84, 91810n (1976).

9. Ogunniyi, D.S. and Odetoye, T.E. , Prepration and evaluation of tobacco seed oilmodified alkyd resins. Bioresource Technology, 99, 1300-1304 (2008).

10. Haghi , A.K., Heat and mass transport through moist porous materials', $14^{\text {th }}$ Int. Symp. on Transport Phenomena, 209-214. (2003).

11. Hakeim, O.A., Nassar, S.H. and Haggag, K., Greener printing of natural color using microwave fixation. Indian Journal of Fiber and Textile Research, 28, June, 216 (2003).

12. Haghi, A.K., Drying process- a theoretical approach. J. Thermal Analysis and Calorimetry, To be Published in volume 74 (2003).

13. Haghi, A.K., The diffusion of heat and moisture through textiles. International Journal of Applied Mechanics and Engineering, 8 (2), 233-243 (2003).

14. Pourova, M. and Vrba, J., Microwave drying of textile materials and optimization of a resonant applicator. Acta polytechnica, 46, (2006). 
15. Aigbodion, A.I. and Okieimen, F.E., Ind. Crops and Prod., 13, 29-34(2001).

16. ZENITECH LLC, Analytical Methods, ZAM-026 -- Acid Value, Old Greenwich, CT 06870 .

17. Essawy. H. A., Studies on the preparation and stability of some urea formaldehyde resin solutions, M.Sc. Thesis Cairo University, Faculty of Science, Chemistry Department, (1996).

18. Schymitzek T. and Esche T., Melliand International, 102 (2), (1997).

19. LAU KC., Dynamic response to color specifications. Journal of Society of Dyer and Colorists, 111(5), 142e5 (1995).

20. AATCC Standard Instrument. North Carolina AATCC (2002).

21. DIN EN ISO 105-CO6, May (1997).

22. DIN EN ISO 105-EO4, June (1986).

23. Kingery, W.D., Bowen, H.K. and Uhlmann, D.R., Introduction to Ceramics, $2^{\text {nd }} \mathrm{ed}$. John Wiley \& Sons, New York (2006).

24. Jeane Dullius, Carlo Ruecker, Vit'oria Oliveira, Rosane Ligabue and Sandra Einloft, Chemical recycling of post-consumer PET: Alkyd resins synthesis. Progress and Organic Coatings, 57, 123-127(2006).

25. Rafael Martinez-Palou, Review, Ionic liquid and microwave-assisted organic synthesis: A "green" and synergic couple. J. Mex. Chem. Soc., 51(4), 252-264 (2007).

26. El-Shimy, N.S., Kashkari, K.R. and Haggag, K. Reducing energy and needed time in acid dyeing of wool via use of microwave. $1^{\text {st }}$ International Conf. of Textile Research Division, NRC, Egypt, March (2004).

27. Doulia, D., Rokotas, S. and Georgopulou, K., Production of alkyd resins and their paints: Effect of catalyst on their properties. Surface Coatings International Part B: Coating Transactions 89(B3),193-268,September (2006).

(Received 10/10/2010 ; accepted 9/1/2011) 


\section{تحضير مواد ربط من مصادر طبيعية باستخدام الميكروويف وتطبيقاتها فى طباعة المنسوجات مصنادر}

نجلاء سبد عبد الحميد الثييمى ، وفاء نيازى إسماعيل ،عيد متولى خليل" ، محمد

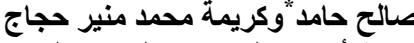
شعبة أبحاث النسيج - المركز القومى مجى للبحوث و *قسم الكيمياء - كلية العلوم -

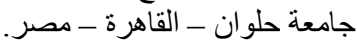

تم تحضير مواد ربط جديدة امنة بيئيا من زيوت طبيعية عن طريق تحضير

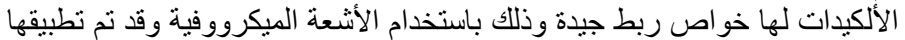

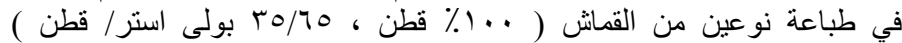

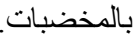

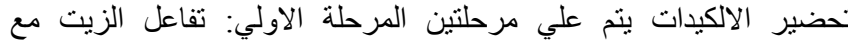

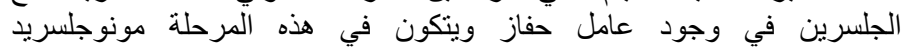
والذي نستدل علي تكونه من خلاز في الال اختبار الكحول الميثيلي (monoglyceride) حتي يعطي محلول نقي تماماوتسمي هذه المرحلة بالالكلة) (Alcoholysis step) الما المرحلة الثانية فيتم فيها اضافة الفيثاليك انهيدريد (

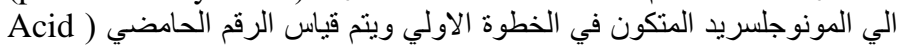
esterification (value

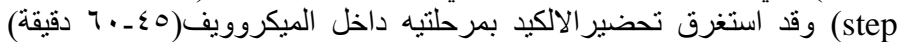

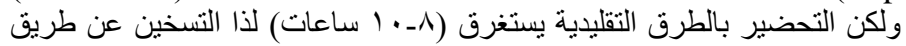

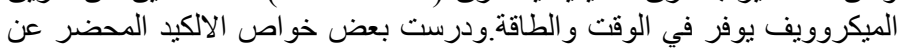

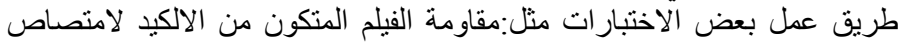

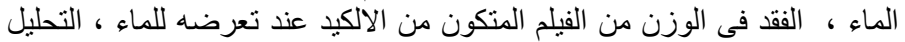

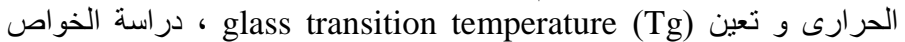
الريولوجية و اللزوجة ، قياس Acid value للالكيد المحضر.

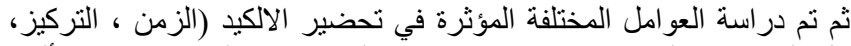

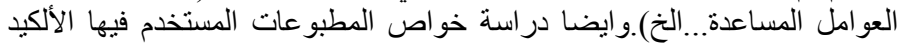

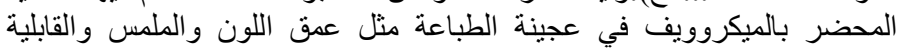
للغسيل و الاحتكالك و العرق و الضوء فئ....الخ. 